$16^{\text {th }}$ International Conference on

AEROSPACE SCIENCES \& AVIATION TECHNOLOGY,

ASAT - 16 - May 26 - 28, 2015, E-Mail: asat@ mtc.edu.eg Military Technical College, Kobry Elkobbah, Cairo, Egypt

Tel : +(202) 24025292 - 24036138, Fax: +(202) 22621908

\title{
Design And Implementation of A PID Controller For A Continuous Stirred Tank Reactor (CSTR) System Using Particle Swarm Algorithms
}

\author{
Magdy A.S. Aboelela \\ Cairo University, Faculty of \\ Engineering, Electric Power and \\ Machines Dept., Giza, Egypt. \\ aboelelamagdy@yahoo.com
}

\author{
Rania Helmy Mansour Hennas \\ Graduate Master Student, Cairo \\ University, Faculty of \\ Engineering, Electric Power and \\ Machines Dept., Giza, Egypt. \\ rony_rany@yahoo.com
}

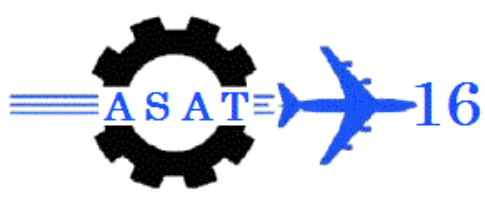

Abstract- This paper introduces the application of PI/PID controller tuned with Particle Swarm Optimization (PSO), Adaptive Weighted Particle Swarm Optimization (AWPSO) algorithms into the field of chemical engineering. The application deals with the temperature and concentration control for Continuous Stirred Tank Reactor (CSTR). The optimization step has been achieved based on three error criterion. They are: Integral of Square Error (ISE), the Integral of Absolute Error (IAE) and the Itegral of Time Absolute Error (ITAE). The temperature and concentration performance of the CSTR has been tested for robustness by changing some of the CSTR parameters. Better performance of the PID tuned by the AWPSO proposed algorithm is noticeable. Also the temperature and concentration performance of the CSTR due to changing some system parameters has been noted in very little values (almost zero) which enrich the idea of the selected PID tuned by the AWPSO for robustness.

Keywords - AWPSO, CSTR, PID Controller, Process Control.

\section{Introduction}

Chemical reactors are the most influential and therefore the important units that a chemical engineer will encounter. To ensure the successful operation of a continuous stirred tank reactor (CSTR), it is necessary to understand their dynamic characteristics. A good understanding will ultimately enable effective control systems design. The aim of these notes is to introduce some basic concepts of chemical reaction systems modeling and develop simulation models for CSTR's. Non-linear and linear systems descriptions are derived [1].

Chemical process control requires intelligent monitoring due to the dynamic nature of the chemical reactions and non- linear functional relationships between the input and output variables are involved. CSTR is one of the major processing units in chemical engineering; such a problem remains too complex to be solved by the known techniques. [2]. 
The problem of controlling of CSTR is considered as an attractive and controversial issue, especially for control engineers, corresponding to its nonlinear dynamic. Most of the conventional controllers are restricted just for linear time invariant system applications. However, in real environment, the nonlinear characteristics of the systems and their functional parameters changes, due to wear and tear, cannot be neglected. Furthermore, dealing the systems with uncertainties in real applications, is the another subject which must be noticed. In this way, the role of the adaptive and intelligent controllers, by the capability of the overcoming the aforementioned points are of the importance. One of the most popular controllers both in the realm of the academic and industrial application is PID. PID controller has been applied in feedback loop mechanism and extensively used in industrial process control since 1950s .Easy implementation of PID controller, made it more popular in system control applications. It tries to correct the error between the measured outputs and desired outputs of the process in order to improve the transient and steady state responses as much as possible. In one hand, PID controller appear to have an acceptable performance in the most of systems, but sometimes there are functional changes in system parameters that need an adaptive based method to achieve more accurate response. Several researches are available that combined the adaptive approaches on PID controller to increase its performance with respect to the system variations [3], [4].

Limitations of traditional approaches in dealing with constraints are the main reasons for emerging the powerful and flexible methods. Bio- inspired intelligent computing has been successfully applied to solve the complex problem in recent years. Genetic algorithm, neural network and fuzzy logic expressed the high capability to overcome the aforementioned issues [5]. Success of the fuzzy logic, which is based on the approximate reasoning instead of crisp modeling assumption, remarks the robustness of this method in real environment application [6].

In both mentioned controllers, PID and fuzzy, the challenge is fine design and tuning in order to achieve accurate and acceptable results. In PID tuning, optimization algorithms such as GA, PSO, and ACO are drastically used to find the optimum values of PID parameters [7], [8] .In addition, these bio-inspired algorithms, can help individual to design desired fuzzy controller [9].

Most of the applications requires controllers be optimally tuned to improve the response in terms of time and output deviations within control range. Historically many algorithms have been utilized to address need to adjust the controller response as close to the desired output as possible, such algorithms encompasses variety of choices from the most primitive, trial and error, to advanced computational intelligence approaches [10-12].

Family of the computational intelligence techniques ranges from Evolutionary Computation (EC) which models natural evolution including genetic and behavioral evolution Fuzzy Systems (FS) which originated from how organisms interact with their environment, Artificial Neural Network (ANN) which models biological neural (Human brain) systems, Swarm Intelligence (SI) which models social behavior of organisms living in swarms which is known as Particle Swarm Optimization (PSO) and the other algorithm is Ant Colony (ACO) and Artificial Immune System (AIS) which models the human immune system [13].

Particle Swarm Optimization (PSO) algorithm is further improved into Adaptive Weighted PSO (AWPSO) later on for enhancing the performance of PSO. 


\section{PID Controller}

PID controller is considered to be a key component of industrial control system because of its capability of improving the dynamic response of the system and reducing the steady state error. PID controller involves three parameters P, I and D where P depends on the present error, I depends on accumulation of past errors and $\mathrm{D}$ is a prediction of future errors based on current rate of change. The transfer function for the PID controller is

$C(s)=k_{p}+\frac{k_{i}}{s}+k_{d} \mathrm{~s}$

\section{Adaptive Weighted Particle Swarm Optimization (AWPSO)}

Particle swarm optimization is one of the swarm intelligence forms in which the behavior of biological social system like a flock of bird or a school of fish [13] is simulated. This algorithm is introduced by Eberhart and Kennedy in 1995 [14-15]. When a swarm looks for food, its particles will spread in the environment and move around independently. Each particle in the swarm flies in the search space with a degree of freedom or randomness in its movements with dynamically adjusted velocity according to its own flying experience and its neighbors flying experience. Each particle is treated as a volume less particle in $G$ dimensional search space [16].

Each particle keeps track of its coordinates in the problem space, which is associated with the best position (solution) it has achieved. This position is called $P_{\text {best }}$. Another best value that is tracked by the global version of the particle swarm optimizer is the overall best value and its location is called $g_{\text {best }}$ obtained by any particle in the swarm. The performance of each particle is evaluated using fitness (cost) function [16]. The PSO is represented mathematically in a form of Particle Velocity $V_{i j}(t)$ and Particle position $X_{i j}(t)$ as follows:

$$
\begin{aligned}
& V_{i j}(t)=\mathrm{W} \cdot V_{i j}(\mathrm{t}-1)+C_{1} \cdot \operatorname{rand}(0,1) \cdot\left(P_{\text {best }}-X_{i j}(\mathrm{t}-1)\right)+C_{2} \cdot \operatorname{rand}(0,1) \cdot\left(g_{\text {best }}-\right. \\
& \left.X_{i j}(\mathrm{t}-1)\right) \\
& \begin{aligned}
X_{i j}(t)= & \left.X_{i j}(t-1)+V_{i j}(t)\right) \\
& i=1,2,3 \ldots, N \\
& j=1,2,3 \ldots, d
\end{aligned}
\end{aligned}
$$

Where

$\begin{array}{lc}V_{i j}(t) & \text { Velocity of the particle } i \text { at iteration } \mathrm{t} ; \\ X_{i j}(t) & \text { Current position of particle } i \text { at iteration } \mathrm{t} ; \\ W & \text { Inertia weight; } \\ C_{l}, C_{2} & \text { Cognitive and social acceleration coefficient; } \\ \text { rand }(0,1) & \text { random number between } 0 \text { and } 1 ; \\ P_{\text {best }} & \text { Particle } i \text { best position; } \\ g_{\text {best }} & \text { Global best position; } \\ N & \text { Number of particles; } \\ d & \text { Dimension; } \\ t & \text { time; }\end{array}$

Adaptive Weighted PSO (AWPSO) algorithm is developed later by Mahfouf [6] for improving the performance of the PSO algorithm. The adaptive weighted PSO is achieved by two terms: Inertia weight (W) and Acceleration factor (A). The inertia weight function is to balance global exploration and local exploration [17]. It controls previous velocities effect on 
the new velocity. Larger the inertia weight, larger exploration of the search space while smaller the inertia weights, the search will be limited and focused on a small region in the search space [18-19]. The inertia weight formula is as follows which makes $\mathrm{W}$ value changes randomly from Wo to 1 :

$$
W=W_{o}+\operatorname{rand}(0,1)\left(1-W_{o}\right)
$$

Where $W_{o}$ is an initial positive constant in the interval $[0,1]$

The Acceleration factor formula is

$$
A=A_{o}+\frac{i}{n}
$$

Where $A_{o}$ is an initial positive constant in the interval $[0.5,1]$

The particle Velocity $V_{i j}(t)$ is rewritten incorporating Acceleration factor as follows:

$V_{i j}(t)=\mathrm{W} \cdot V_{i j}(\mathrm{t}-1)+\mathrm{A} \cdot C_{1} \cdot \operatorname{rand}(0,1) \cdot\left(P_{\text {best }}-X_{i j}(\mathrm{t}-1)\right)+A \cdot C_{2} \cdot \operatorname{rand}(0,1) \cdot\left(g_{\text {best }}-\right.$ $\left.X_{i j}(\mathrm{t}-1)\right)(\mathbf{8})$

\section{PI/PID controller Tuning procedure using AWPSO}

The search procedures of the AWPSO for finding the optimal values of the PID controller are as follows:

Step 1: Specify upper and lower bound of the PID controller parameter. The upper and lower bound values depend on the controlled system characteristics.

Step 2: Initialize randomly the particles position and velocity.

Step 3: Calculate the values of the cost function in the time domain.

Step 4: Compare each particle evaluation values with its best position $P_{\text {best }}$. The best evaluation value among the $P_{\text {best }}$ value is denoted as $g_{\text {best }}$.

Step 5: Update the velocity of each particle in the swarm according to the following formula

$$
\begin{aligned}
& V_{i j}(t)=\mathrm{W} \cdot V_{i j}(\mathrm{t}-1)+\mathrm{A} \cdot C_{1} \cdot \operatorname{rand}(0,1) \cdot\left(P_{b e s t}-X_{i j}(\mathrm{t}-1)\right)+\quad A \cdot C_{2} \cdot \operatorname{rand}(0,1) \cdot\left(g_{\text {best }}-\right. \\
& \left.X_{i j}(\mathrm{t}-1)\right) \quad(9)
\end{aligned}
$$

Step 6: Update the position of each particle in the swarm according to the following formula

$$
\left.X_{i j}(t)=X_{i j}(t-1)+V_{i j}(t)\right)
$$

Step 7: Update particle best position and global best position.

Step 8: Repeat the cycle again until maximum number of iteration is reached.

Step 9: When the number of iteration reaches its maximum value, then the latest global best position value is considered as the optimal value for the controller parameter. 


\section{Applications : Temperature Control For CSTR}

The chemical reactor is commonly used in chemical industry and it is a complex device where mass transfer, diffusion, heat transfer along with chemical reaction may occur, so this device should be controllable and safe [22]. Continuous stirred chemical reactor (CSTR) system [2223] has been used where irreversible exothermic chemical reaction takes place. The heat generated from the chemical reaction is controlled via cooling jacket surrounding the reactor [24]. First, the fluid enters the reactor reacting with the medium inside the reactor, then mixed well and leaves the reactor through exit valve. CSTR system is shown in Figure 1.

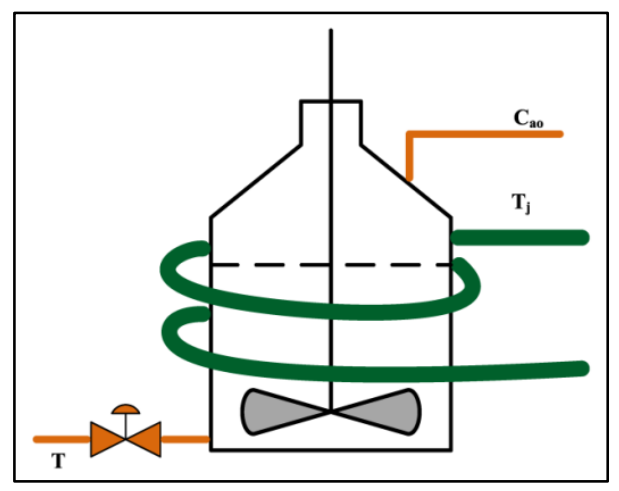

Figure 1: The CSTR Model

The CSTR system shown in Figure 2 is represented mathematically by equation 11 and 12 .

$$
\begin{gathered}
\frac{d C_{a o}}{d t}=\frac{Q}{V} \cdot\left(C_{a o}-C_{a}\right)-K_{o} \cdot \exp \left[\frac{-E}{R T}\right] \cdot C_{a} \\
\frac{d T}{d t}=\frac{Q}{V} \cdot\left(T_{o}-T\right)-\left(\frac{\Delta H}{\rho \cdot C_{p}}\right) \cdot K_{o} \cdot \exp \left[\frac{-E}{R T}\right] \cdot C_{a}-\left(\frac{U \cdot A}{V \cdot \rho \cdot C_{p}}\right) \cdot\left(T-T_{j}\right)
\end{gathered}
$$

CSTR system is represented in a form of closed loop block diagram in Figure 2.

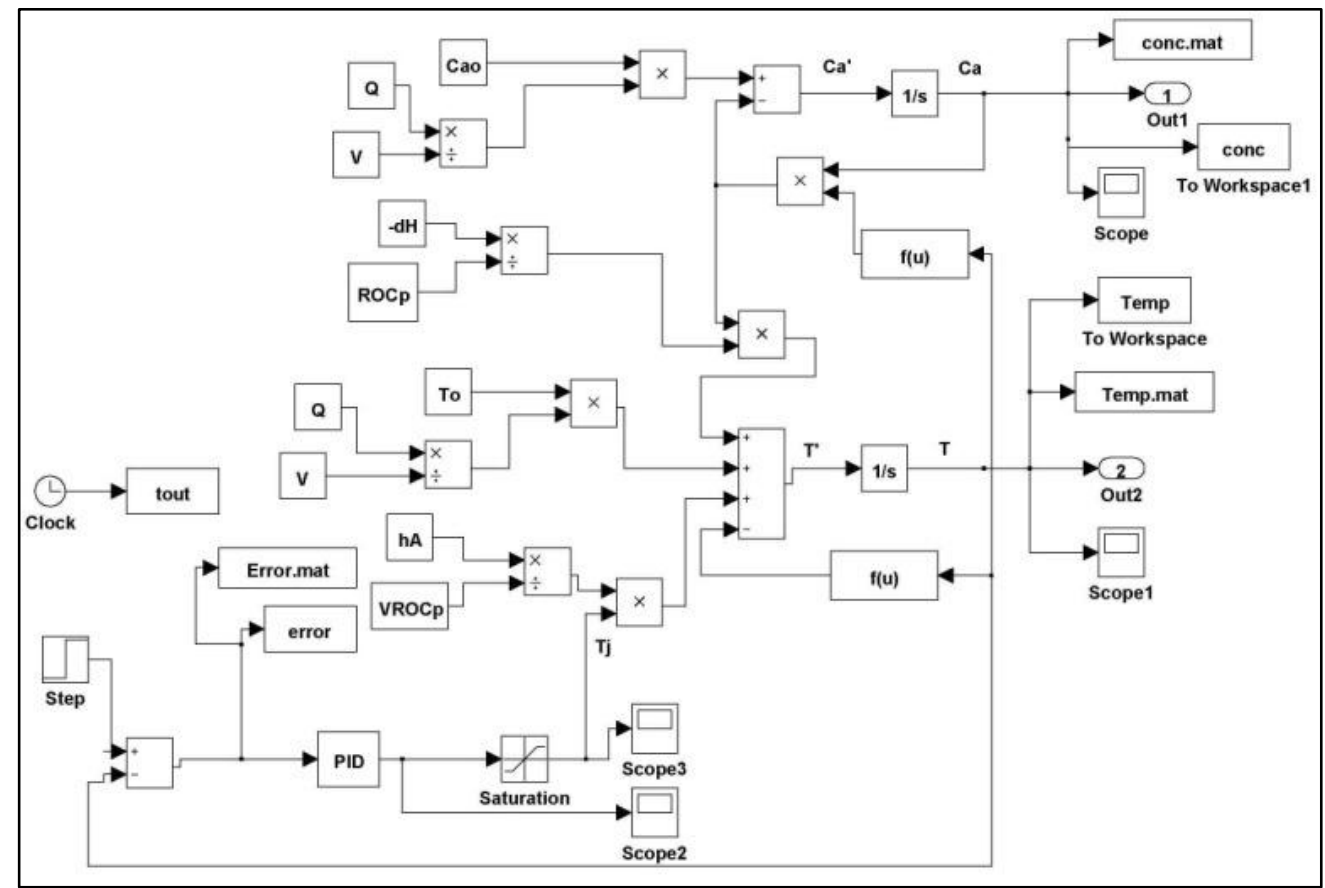

Figure 2: The CSTR Model block diagram 


\section{B1. The CSTR model objective function}

The control objective is to maintain the chemical reaction temperature at a desired value which is $350{ }^{\circ} \mathrm{C}$ in our case.

Error signal from the system will be taken as an input to the controller and performance indices are utilized as objective function. The objective function is as follows.

For IAE

$$
I A E=\int_{0}^{\infty}|e(t)| d t
$$

For ISE

For ITAE

$$
I S E=\int_{0}^{\infty}\left|e^{2}(t)\right| d t
$$

$$
\operatorname{ITAE}=\int_{0}^{\infty} t|e(t)| d t
$$

\section{B2. The CSTR model Parameters Values}

The description and the values of the CTSR model parameters indicated in the block diagram are listed in Table 1.

Some abbreviation shown in the block diagram in Figure 2 deviate from what is shown in Table 11 noted as follows: $\Delta \mathrm{H}$ in the table is $\mathrm{dH}$ in the block diagram and $\rho$ in the table is $\mathrm{RO}$

\begin{tabular}{|c|c|c|}
\hline $\begin{array}{c}\text { Parameter } \\
\text { name }\end{array}$ & Description & Value \\
\hline$Q$ & Process flow rate $\left(1 \mathrm{~min}^{-1}\right)$ & 100 \\
\hline $\boldsymbol{V}$ & Reactor volume (l) & 100 \\
\hline$C_{a o}$ & Feed fluid concentration $\left(\mathrm{mol} \mathrm{l}^{-1}\right)$ & 1 \\
\hline$C_{a}$ & CSTR output fluid concentration $\left(\mathrm{mol} \mathrm{l}^{-1}\right)$ & varying \\
\hline$K_{o}$ & Reaction rate constant $\left(\mathrm{min}^{-1}\right)$ & $7.2 \times 10^{10}$ \\
\hline$\frac{E}{R}$ & Activation energy term $(\mathrm{K})$ & $10^{4}$ \\
\hline$T_{o}$ & Feed fluid temperature $(\mathrm{K})$ & 350 \\
\hline$T$ & Chemical reaction (output) temperature $(\mathrm{K})$ & varying \\
\hline$T_{j}$ & Coolant temperature $(\mathrm{K})$ & varying \\
\hline$\Delta H$ & Heat of reaction $\left(\mathrm{cal} \mathrm{mol}^{-1}\right)$ & $-2 \times 10^{5}$ \\
\hline $\boldsymbol{h A}$ & Heat transfer term $\left(\mathrm{cal} \mathrm{min} \mathrm{m}^{-1} \mathrm{~K}^{-1}\right)$ & $7 \times 10^{5}$ \\
\hline$\rho$ & Fluid density $\left(\mathrm{gl}^{-1}\right)$ & $10^{3}$ \\
\hline$C_{p}$ & Specific heat $\left(\mathrm{cal} \mathrm{g}^{-1} \mathrm{k}^{-1}\right)$ & 1 \\
\hline
\end{tabular}
in the block diagram.

Table 1: The CSTR model Parameters Values

\section{B3. The CSTR model Simulation}

The CSTR model is tested using, firstly, the PID controller tuned by PSO and AWPSO and, secondly, implementing the PI controller tuned by PSO and AWPSO. The reactor temperature graphs are displayed with PID and PI controller tuned with PSO and AWPSO. This can be displayed in Figures 3 to 6 (system temperature) and Figure 7 (system concentration) given below. This has been achieved using different error criterion such as IAE, ISE, and IATE. 
Moreover, the changes of the error signal as shown in Figure 2 (error) using PID and PI controllers tuned by PSO and AWPSO has been investigated in our work. The results illustrated in Figures 8 and 9 show the behavior of the error signal obtained as a results of the three error criterion; IAE, ISE, and ITAE. These error criterion have been invoked in the tuning process of either PI or PID controller using PSO or AWPSO techniques. The change of the error signal tends for zero at the end of the performance time (steady state). But, this steady state performance can not be achieved without applying the controller. This is apparent in Figure 8 to 9.

Furthermore, two system parameters have been chosen to testify the tuned controller's robustness. Firstly, process flow rate $\left(1 \mathrm{~min}^{-1}\right), \boldsymbol{Q}$, as described in Table 1 . It has been changed from 100 to 200. The new response is delineated in Figure 10. Secondly, Fluid density $\left(\mathrm{gl}^{-1}\right)$, $\rho$, as described in Table 1. It has been changed from $10^{3}$ to $10^{4}$. The new response is delineated in Figure 11. This show the robustness on the proposed technique to the system parameter changes. No great change in the temperature curve of the CSTR is noted. The same results has been obtained with the concentration curve. This is almost for all error criterion.

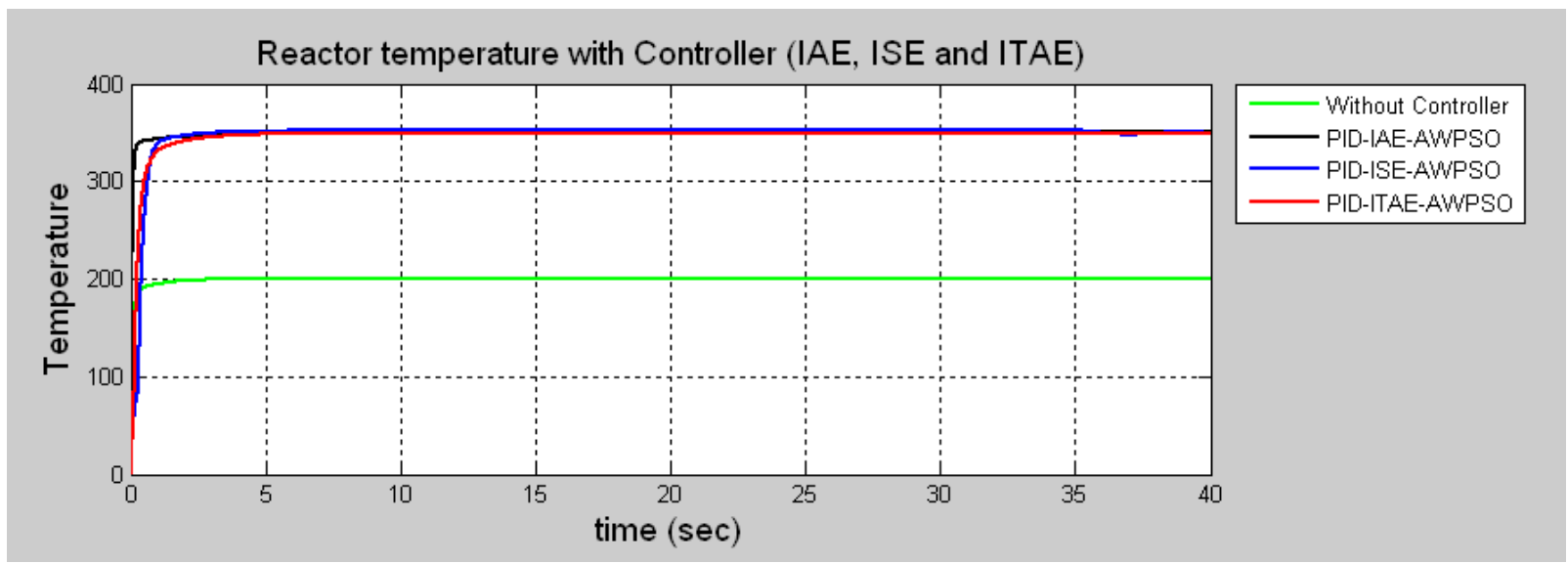

Figure 3: Reactor Temperature with PID-AWPSO and Different Error Criterion

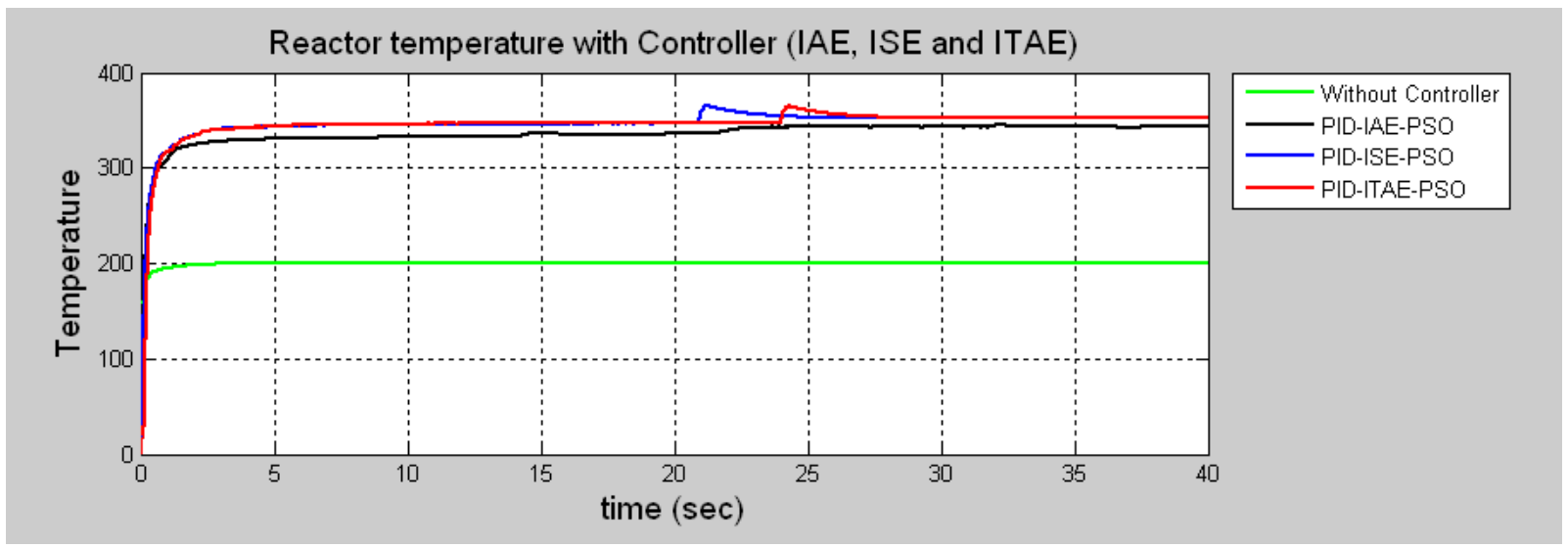

Figure 4: Reactor Temperature with PID-PSO and Different Error Criterion 


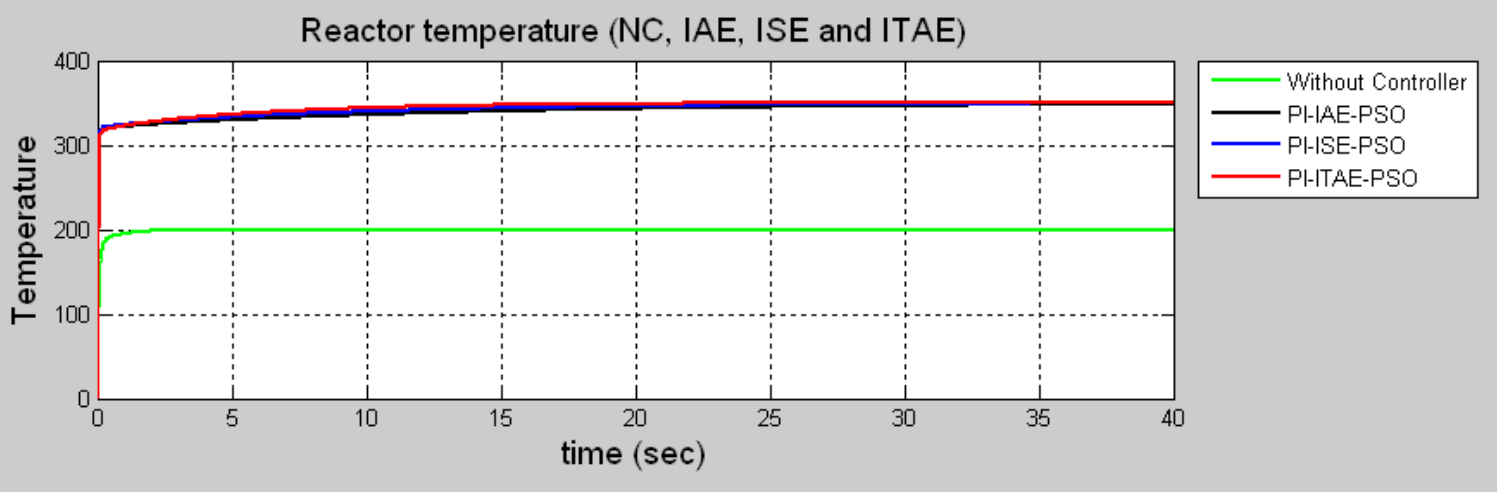

Figure 5: Reactor Temperature with PI-PSO and Different Error Criterion

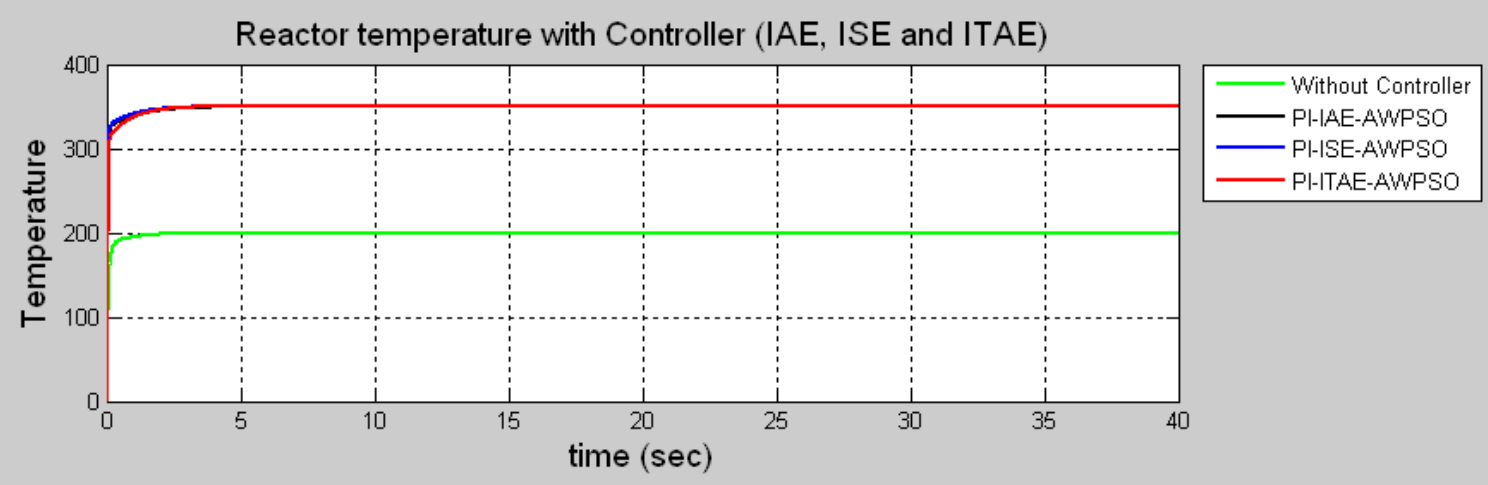

Figure 6: Reactor Temperature with PI-AWPSO and Different Error Criterion

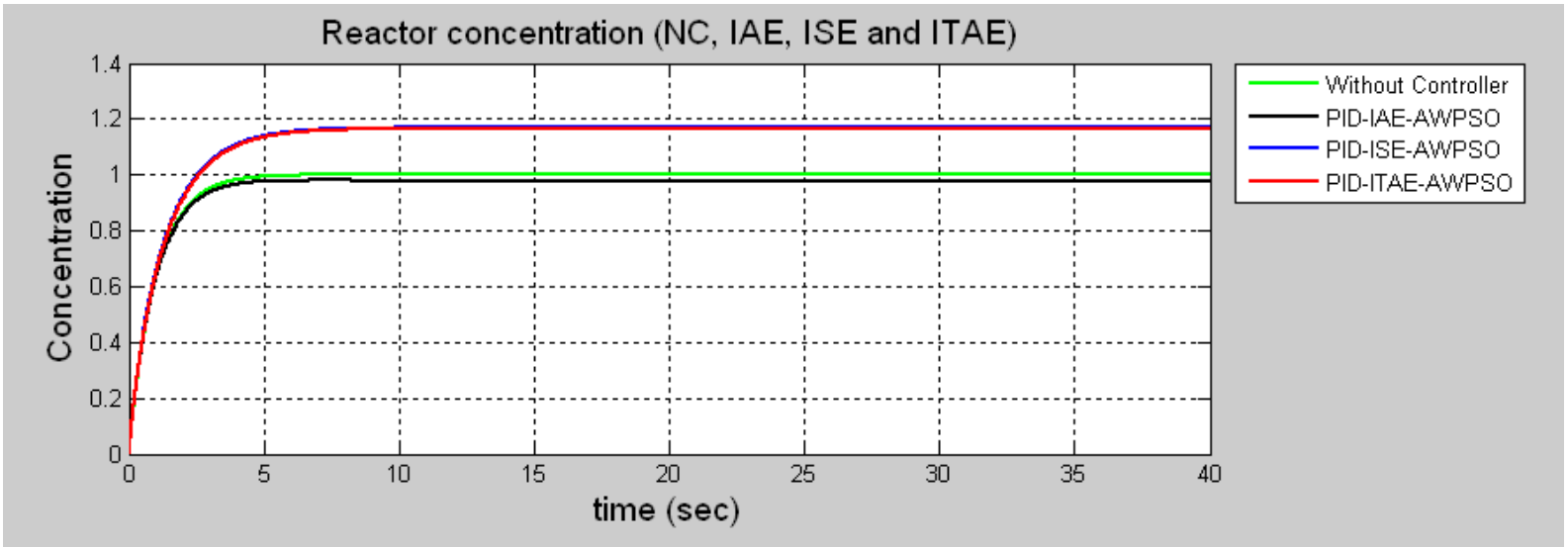

Figure 7: Reactor Concentration with PID-AWPSO and Different Error Criterion

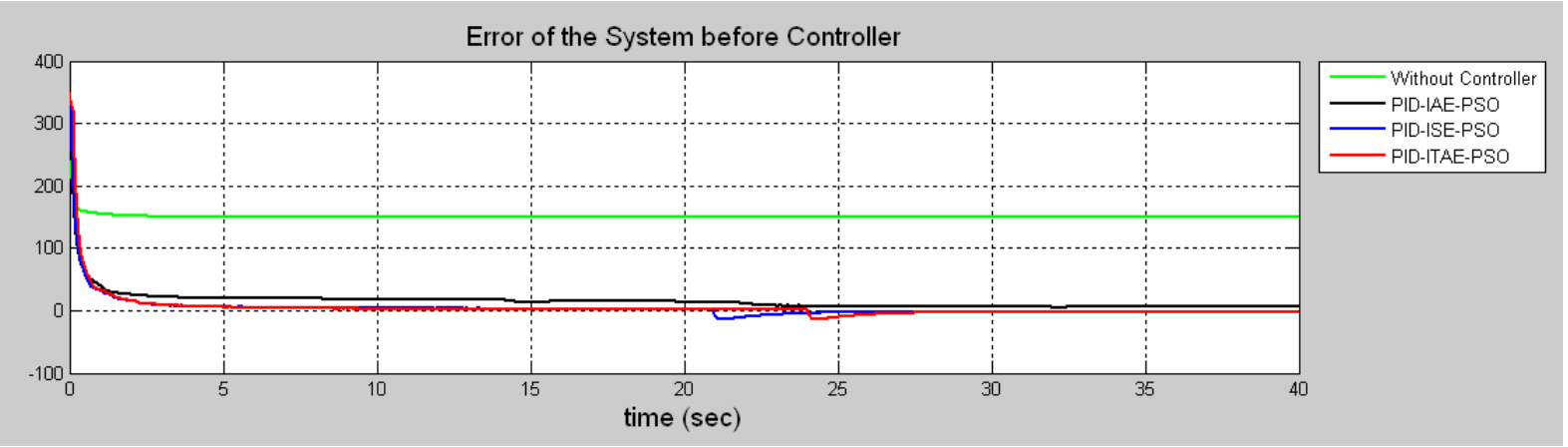


Figure 8: Change of the Temperature Error Signal of the Reactor with PID-PSO and Different Error Criterion

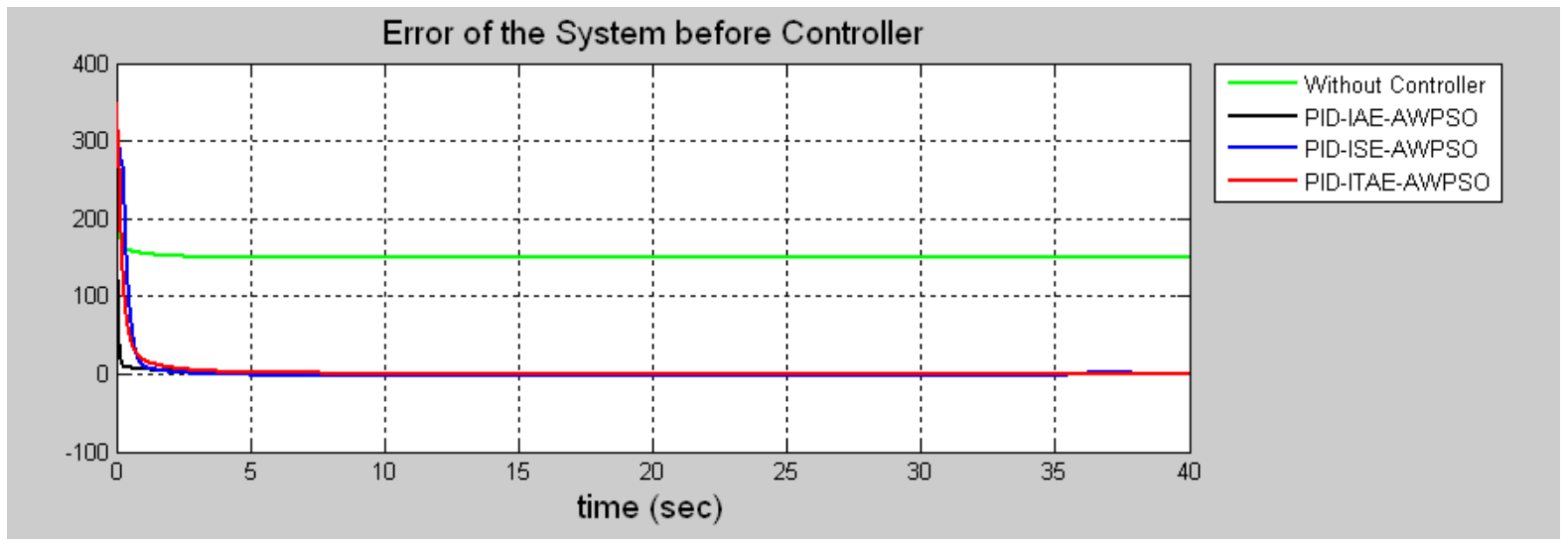

Figure 9: Change of the Temperature Error Signal of the Reactor with PID-AWPSO and Different Error Criterion

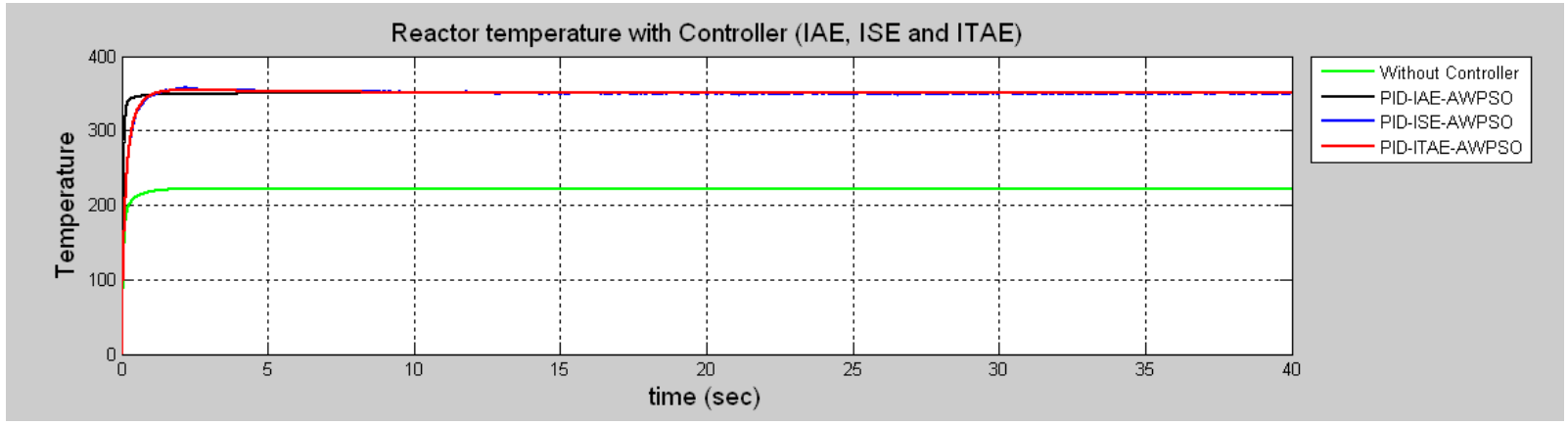

Figure 10: Reactor Temperature with PID-AWPSO and Different Error Criterion ( $Q$ of Table 1 has been changed to $2001 \mathrm{~min}^{-1}$ )

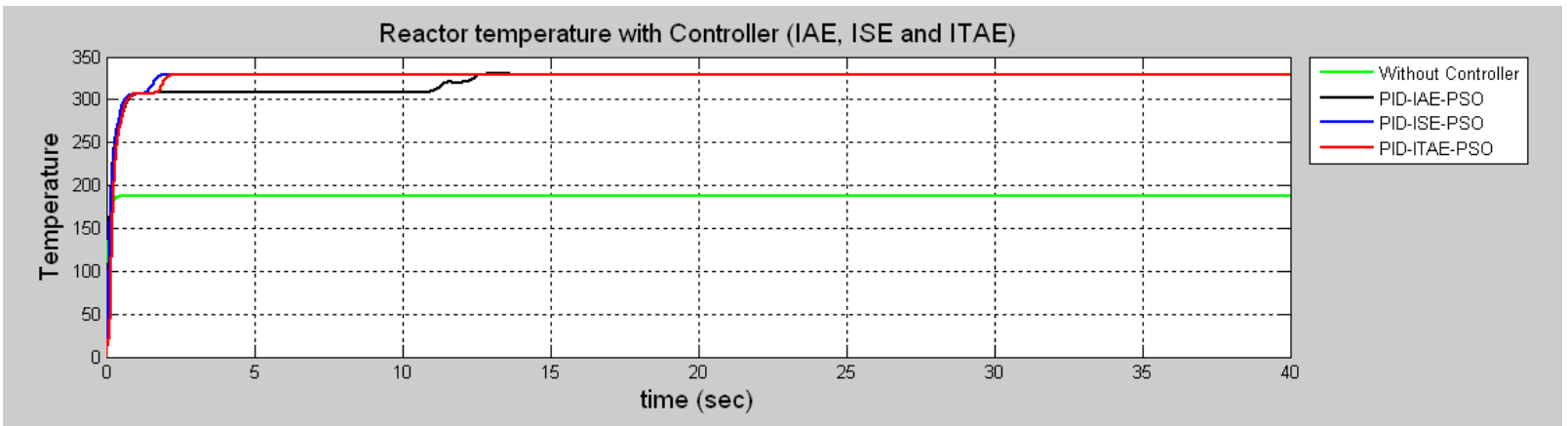

Figure 11: Reactor Temperature with PID-PSO and Different Error Criterion ( $\rho$ of Table 1 has been changed to $10^{4} \mathrm{gl}^{-1}$ )

The settling time, overshoot, undershoot values along with PID controller gains values are mentioned in Table 2. 
Table 2: The CSTR model Simulation results with PID-AWPSO

\begin{tabular}{|c|c|c|c|}
\hline Description & IAE & ISE & ITAE \\
\hline settling time & 7.7262 & 3.5344 & 3.1468 \\
\hline undershoot & No overshoot & No overshoot & No overshoot \\
\hline $\boldsymbol{K}_{\boldsymbol{p}}$ & 8.1472 & 8.5234 & 1.5354 \\
\hline $\boldsymbol{K}_{\boldsymbol{i}}$ & 2.7603 & 5.8639 & 4.1431 \\
\hline $\boldsymbol{K}_{\boldsymbol{d}}$ & 1.6218 & 0.3033 & 2.5249 \\
\hline
\end{tabular}

The settling time, overshoot, undershoot values along with PI controller gains values are mentioned in Table 3.

Table 3: Simulation results with PI-AWPSO

\begin{tabular}{|c|c|c|c|}
\hline Description & $\boldsymbol{I A E}$ & $\boldsymbol{I S E}$ & $\boldsymbol{I T A E}$ \\
\hline settling time & 3.0487 & 1.3171 & 2.4281 \\
\hline undershoot & No overshoot & No overshoot & No overshoot \\
\hline $\boldsymbol{K}_{\boldsymbol{p}}$ & 7.2637 & 4.2064 & 5.3863 \\
\hline $\boldsymbol{K}_{\boldsymbol{i}}$ & 3.9753 & 6.8690 & 4.4374 \\
\hline
\end{tabular}

\section{B4. AWPSO Parameters for the CSTR model}

The chosen AWPSO parameters values for the CSTR Model are listed in Table 4.

Table 4: AWPSO Parameters

\section{B5. Summary for the CSTR model Simulation}

\begin{tabular}{|c|l|}
\hline parameters & Value \\
\hline $\boldsymbol{N}$ & 50 particles \\
\hline $\boldsymbol{n}$ & 200 iterations \\
\hline $\boldsymbol{d}$ & 3 variables \\
\hline $\boldsymbol{C}_{\boldsymbol{I}}$ & 1.2 \\
\hline $\boldsymbol{C}_{\boldsymbol{2}}$ & 1 \\
\hline $\boldsymbol{W}_{\boldsymbol{o}}$ & 0.5 \\
\hline $\boldsymbol{A}_{\boldsymbol{o}}$ & 0.5 \\
\hline $\boldsymbol{X}_{\text {Orange }}$ & {$[010]$} \\
\hline
\end{tabular}

For control purposes, the CSTR model was tested, firstly, based on the PID tuned by AWPSO controller and secondly with PI tuned AWPSO controller. The simulation result shows that for both PID and PI based AWPSO controllers, there are no spikes or dips appeared in the output response whereas the system reaches steady state smoothly. However, the system response is slower with PID than with PI controller for IAE, ISE and ITAE performance indices.

\section{Discussion and Conclusion}

This paper presents the design of PI/PID controllers tuned by PSO and Adaptive Weighted Particle Swarm Optimization (AWPSO) algorithms. This control approach has proven its efficient performance through application on the CSTR model. It is tested differently by comparing the PI and PID tuned by PSO and AWPSO .

The temperature and concentration performance of the CSTR has been tested for robustness by changing some of the CSTR parameters. Better performance of the PID tuned by the AWPSO proposed algorithm is noticeable. Also the temperature and concentration 
performance of the CSTR due to changing some system parameters has been noted in very little values (almost zero) which enrich the idea of the selected PID tuned by the AWPSO for robustness.

The changes of the error signal as shown in Figure 2 (error) using PID and PI controllers tuned by PSO and AWPSO has been investigated in our work. The results illustrated show the behavior of the error signal obtained as a results of the three error criterion; IAE, ISE, and ITAE. The change of the error signal tends for zero at the end of the performance time (steady state). But, this steady state performance cannot be achieved without applying the controller.

It is clear that the proposed control approach is capable of reducing settling time with a measurable value. Furthermore, the overshoots, undershoots and ripples are minimized obviously. The difficulties faced in utilizing AWPSO was choosing the appropriate AWPSO parameters to suit the model in the presence of non-linearity in systems models. In addition to specifying the suitable objective function along with the controller gains.

\section{References}

[1]. Willis M.J., Continuous stirred tank reactor models. Technical Report. Dept. of Chemical and Process Engineering and Process Engineering, University of Newcastle, March, 2000.

[2]. Himmelblau D. M. Fault detection and diagnosis in chemical and Journal of Theoretical and Applied Information Technology, 1978.

[3]. S.F.Rezeka, N.M.Elsodany, and N.A.Maharem, "Fuzzy Gain Scheduling Control of a Stepper Motor Driving a Flexible Rotor", European Journal of Scientific Research , Vol.39, pp.50-63,2010.

[4]. S.Kamalasadan, "A New I intelligent Control for the Precision Tracking of Permanent Magnet Stepper Motor", IEEE, Power Engineering Society General Meeting, 2007.

[5]. K.R.Krishnand ,S.H.Nayak ,"Comparative Study of Five Bio-Inspired Evolutionary Optimization Techniques", World Congress on Nature \& Biologically Inspired Computin, 2009.

[6]. R.Ketata , D.Geest, and A.Titli , " Fuzzy Controller : Design ,Evaluation, Parallel and Hierarchical Combination with a PID Controller”, journal of Fuzzy Sets and Systems, vol 71,pp. 113129,1995 .

[7]. M. Obaid Ali, S. P. Koh, and K. H. Chong, S.K.Tiong and Z. Assi Obaid, "Genetic Algorithm Tuning Based PID Controller for Liquid-Level Tank System", Proceedings of the International Conference on Man-Machine Systems, MALAYSIA, 2009.

[8]. Babita Majhi, G. Panda, "Development of efficient identification scheme for nonlinear dynamic systems using swarm intelligence techniques", Journal of Expert Systems with Applications, vol 37, pp. 556-566,2010 .

[9]. Y. Yuan,H. Zhuang ,"A Genetic Algorithm for Generating Fuzzy Classification Rules", Journal of Fuzzy Sets and Systems, Vol 84, pp.1-19,1996.

[10]. U. Sabura Banu , G. Uma, "Fuzzy Gain Scheduled Pole Placement Based State Feedback Control of CSTR" , International Conference on Information and Communication Technology in Electrical Science,.2007.

[11]. U. Sabura Banu, G. Uma, "ANFIS Gain Scheduled CSTR with Genetic Algorithm Based PID Minimizing Integral Square Error", International Conference on Information and Communication Technology in Electrical Science,.2007

[12]. M. Nikravesh ,A.E. Farell,T.G. Stanford, " Control of nonisothermal CSTR with time varying parameters via dynamic neural network control (DNNC) ", Chemical Engineering Journal,vol 76,pp.116,2000 .

[13]. Kennedy.J and Russell C. Eberhart, "Swarm Intelligence", Morgan-Kaufmann, pp 337-342, 2001. 
[14]. Eberhart, R. C. and Kennedy. J, “A new optimizer using particle swarm theory", Proceeding of the Sixth International Symposium on Micro Machine and Human Science. Nagoya, Japan, pp. 3943, 1995.

[15]. Kennedy, J. and Eberhart, R. C, "Particle swarm optimization", Proc. IEEE Int'l conf. on Neural Networks, Piscataway, NJ: IEEE Press, IV pp.1942-1948, 1995.

[16]. Zwe-Lee Gaing, "A Particle swarm optimization approach for optimum design of PID controller in AVR system", IEEE Transactions on Energy Conversion, 19:384 - 391, 2004.

[17]. S. N. Sivanadam, P. Visalakshi, "Multiprocessor using Hybrid Particle swarm optimization with Dynamically Varying inertia", International Journal of computer science and applications, PP 95106, 2007.

[18]. Mahfouf, M., Minyou-Chen, D. A. Linkens, "Adaptive Weighted Particle Swarm Optimization (AWPSO) of Mechanical Properties of Alloy Steels", 8th International Conference on Parallel Problem Solving from Nature (PPSN VIII), Birmingham (U.K), 2004.

[19]. Xiaohui Hu, Russel Eberhart, Yuhui shi, "Recent advances in particle swarm", Proceeding of the congress on evolutionary computation (CEC-2004), Vol. 1, Piscataway, IEEE Service Center, pp.90-97, 2004.

[20]. K.sabahi, A. sharifi, M. Aliyari, M. Teshnehlab and M. Aliasghary, "Load frequency control in interconnected power system using Multi-objective PID controller", Journal of Applied Sciences, pp. 1-7, 2008.

[21]. C. Agees Kumar, N. Kesavan Nair, "Multi-objective PID Controller based on Adaptive Weighted PSO with Application to Steam Temperature control in Boilers", International Journal of Engineering Science and Technology, 2010.

[22]. Mohd Fuaad Rahmat, "Temperature control of a continuous stirred tank reactor by means of two different intelligent strategies", International Journal on smart sensing and intelligent systems, Vol.4, No. 2, June 2011.

[23]. Dale E. Seborg, Thomas F. Edgar, Duncan A. Mellichamp, "Process Dynamics and Control", Second edition, Wiley, 2004.

R. Vinodha S. Abraham and J. Prakash, "Multiple model and neural based adaptive multi loop PID controller for a CSTR process", International Journal of Electrical and Computer Engineering 5:4, 2010. 